\title{
Fine-scale patterns of vegetation assembly in the monitoring of changes in coastal sand-dune landscapes
}

\author{
J. Honrado, J. Vicente, A. Lomba, P. Alves, J. A. Macedo, R. Henriques, H. Granja and F. B. Caldas
}

Honrado, J., Vicente, J., Lomba, A., Alves, P., Macedo, J. A., Henriques, R., Granja, H. and Caldas, F. B. 2010. Fine-scale patterns of vegetation assembly in the monitoring of changes in coastal sand-dune landscapes. - Web Ecol. 10: 1-14.

\begin{abstract}
Understanding dune ecosystem responses to multi-scale environmental changes can provide the framework for reliable forecasts and cost-efficient protocols for detecting shifts in prevailing coastal dynamics. Based on the hypothesis that stress and disturbance interact as primary community controls in coastal dunes, we studied the fine-scale floristic assembly of foredune vegetation, in its relation to topography, along regional and local environmental gradients in the $200 \mathrm{~km}$ long coastline of northern Portugal, encompassing a major biogeographic transition in western Europe. Thirty topographic profiles perpendicular to the shoreline were recorded at ten sites along the regional climate gradient, and vegetation was sampled by recording the frequency of plant species along those profiles. Quantitative topographic attributes of vegetated dune profiles (e.g. length or height) exhibited wide variations relatable to differences in prevailing coastal dynamics. Metrics of taxonomic diversity (e.g. total species richness and its additive beta component) and of the functional composition of vegetation were highly correlated to attributes of dune topography. Under transgressive dynamics, vegetation profiles have fewer species, increased dominance, lower turnover rates, and lower total vegetation cover. These changes may drive a decrease in structural and functional diversity, with important consequences for resistance, resilience and other ecosystem properties. Moreover, differences in both vegetation assembly (in meta-stable dunes) and response to increased disturbance (in eroding dunes) between distinct biogeographic contexts highlight a possible decline in facilitation efficiency under extreme physical stress (i.e. under Mediterranean climate) and support the significance of functional approaches in the study of local ecosystem responses to disturbance along regional gradients. Our results strongly suggest that assessing fine-scale community assembly can provide insights on the relation between dune vegetation, environmental filters and ecosystem processes. A combination of cost-efficient indicators from dune topography and vegetation is thus suggested as a promising approach to survey, forecast and monitor changes in coastal dune ecosystems.
\end{abstract}

J. Honrado (jhonrado@fc.up.pt), J. Vicente, A. Lomba, P. Alves, J. A. Macedo, and F. B. Caldas, CIBIO-Centro de Investigação em Biodiversidade e Recursos Genéticos and Depto de Botânica da Faculdade de Ciências, Univ. do Porto. Edificio FC4, Rua do Campo Alegre s/n, PT-4169-007 Porto, Portugal. - R. Henriques, H. Granja, Depto de Ciências da Terra, Univ. do Minho. Campus de Gualtar, PT-4710-057 Braga, Portugal. RH and HG also at: CGUP Centro de Geologia, Univ. Porto, Rua do Campo Alegre, PT-4169-007 Porto, Portugal. 
Coastal landscapes are highly dynamic systems predicted to be severely impacted by global environmental changes (Urbanski 2001, Davidson-Arnott 2005, Feagin et al. 2005a, Christian and Mazzilli 2007), e.g. due to sea-level rise and related shifts in sediment budgets, shoreline location, water balance and diversity of biological communities (Greaver and Sternberg 2007). Processes related to global warming are expected to carry important consequences for coastal areas (MEA 2005, Kerr 2007), including the destruction of habitats, ecosystem invasion by alien species (Thuiller 2007), modifications on coastal hydrogeology and landward shift of dune vegetation (Greaver and Sternberg 2007).

Coastal dunes are among the most important ecosystems on earth, both in terms of their biological diversity (Acosta et al. 2005, Adger et al. 2005) and regarding the provision of environmental services with ecologic and economic relevance (Wilson et al. 2005, Martínez et al. 2007, Schlacher et al. 2007). However, coastal dunes are also known to be extremely vulnerable to disturbance, both natural and anthropogenic (Martínez et al. 2006), which can locally enhance the effects of global environmental changes. There is still limited knowledge on the responses of coastal vegetation to habitat loss or restriction, even though a breakdown of the beach-dune dynamics as a result of erosion is widely acknowledged (Feagin et al. 2005a, IPCC 2007). Given their front-shore location, foredunes (the foremost dune ridges formed by sand accretion) are most affected by several kinds of environmental stress and are most exposed to disturbance by random extreme occurrences (Hesp and Martínez 2007, Levin et al. 2008).

Coastal dunes usually host peculiar plant species and vegetation types, and high levels of endemicity are common (Lomba et al. 2008). The ability to predict impacts of disturbances on dune ecosystem composition, structure and function is dependent on the level of understanding of interactions among species and between these and their environment, such as the processes related to sand burial and the mechanisms of facilitation among species (Bruno et al. 2003, Franks and Peterson 2003). Ecosystem processes in coastal dune landscapes are constrained by strong environmental stress gradients (e.g. salinity, wind speed, radiation, substrate mobility, nutrients, and biotic pressures, Hesp and Martinez 2007, Forey et al. 2008, Levin et al. 2008), so they can be considered true 'gradient landscapes' (sensu McGarigal and Cushman 2005). These gradients determine the organization of vegetation profiles along a succession of characteristic geomorphologic features from the beach inwards (Feagin et al. 2005b, Lomba et al. 2006, 2008, Greaver and Sternberg 2007, Lortie and Cushman 2007). For this reason, the quantification of vegetationgeomorphology interactions is considered crucial in the assessment of impacts of environmental changes, including the establishment of reliable indicators (Baas and Nield 2007, Levin et al. 2008, Lomba et al. 2008). Even though worldwide vegetation zonation in foredunes has been demonstrated decades ago (Doing 1985) and extensively confirmed in recent years (Wilson and Sykes 1999, Dech and Maun 2005, Isermann 2005, Levin et al. 2008, Lomba et al. 2008), the actual factors driving that zonation are yet controversial due to covariance and interaction among environmental factors (Dech and Maun 2005, Forey et al. 2008). Nonetheless, a close relation between vegetation and sediment transport/deposition in coastal dunes has been reported by a number of authors (Maun and Perumal 1999, Baas 2007, Meerkerk et al. 2007, Levin et al. 2008). This relationship can provide deeper insights into the dynamics of dune landscapes, which can then support a range of applications in management, monitoring and restoration (Levin et al. 2006, Baas and Nield 2007).

In this context, sand dunes are among the most extensively studied types of ecosystems, and bioindication by vegetation attributes has been stressed as an obvious reality in these habitats (García-Mora et al. 1999, Lomba et al. 2006, 2008). However, detailed, fine-scale assessments of community assembly and dynamics, in their relation to environmental gradients and pressures, are still required if a wide use of vegetation in the monitoring of changes in coastal areas is intended. García-Mora et al. (1999) and Feagin and Wu (2007) demonstrated how such fine-scale approaches, based on a combination of taxonomic and functional diversity data, can provide evidence on community assembly and vegetation responses to disturbance. Also, Forey et al. (2008) provided solid evidence that stress and disturbance primarily act as community controls at different scales, but also that they interact in determining dune vegetation assembly.

In order to assess the implications of multi-scale environmental filters of community assembly for bioindication of changes in coastal sand dunes, we studied the fine-scale floristic assembly of foredune vegetation, in its relation to dune topography, along regional (climate and biogeography) and local (distance to shoreline) environmental gradients. We build on the assumption that topographic modifications of the beach-foredune system can be used as a surrogate of increased ecosystem disturbance related to coastal erosion (Levin et al. 2006), and that understanding fine-scale vegetation responses to such modifications can provide a framework for reliable and cost-efficient monitoring methodologies concerned with changes in coastal dynamics and the putative impacts of sea-level rise, increased storminess and other processes related to global climate change. The following three questions were addressed sequentially: 1) can synthetic quantitative attributes of topographic profiles be used as indicators of predominant local dynamics?, 2) which features of vegetation assembly are most influenced by variations in topography, and how is local vegetation response to those variations influenced by regional gradients?, and 3) can cost-efficient indicators of prevailing coastal dynamics be derived from fine-scale vegetation-topography assessments? 


\section{Material and methods}

\section{Study area}

Field surveys were conducted along the northern coastline of mainland Portugal, a $200 \mathrm{~km}$ long, highly energetic (Coelho et al. 2009) sand-dune dominated coastal area approximately centred in the city of Porto (Fig. 1), at latitudes between $40^{\circ} 13^{\prime} \mathrm{N}$ and $41^{\circ} 40^{\prime} \mathrm{N}$. Most of this coastline is naturally suffering retreat (i.e. transgressive dynamics), with natural barriers (e.g. submerged rocks) and coastal defence constructions exhibiting local positive impacts on sand accumulation at their northward faces (due to predominant north-south drift direction), though in most cases negative impacts are perceived southwards of such barriers.

The climate is sub-Mediterranean to Mediterranean (sensu Rivas-Martínez et al. 2002), typically with two to three dry months in summer and heavy winter rainfall (total rainfall ranging from ca $800 \mathrm{~mm}_{\text {year }}{ }^{-1}$ in the extreme south to ca $1500 \mathrm{~mm}_{\text {year }}^{-1}$ in the northern areas); morning fog and mist are frequent. Temperatures are mild, with mean annual temperatures of $14-15^{\circ} \mathrm{C}$ throughout the area. The predominant winds are from north and northwest. However, the strongest winds are usually from south and southwest, and $95 \%$ of waves come from north and west.

Though quantitative data about aeolian sediment transport in this coastal sector is scarce (Sherman et al. 2007), beach-dune geomorphology in northern Portugal has been established in previous studies (Granja and Carvalho 1992, Granja 1997, Loureiro and Granja 2001), which identified a common structure with four major strands (beach, embryonic foredunes, foredunes, and interior dunes) running parallel to the shoreline. In the northernmost coastal sector, narrow dunes of medieval to sub-recent ages occur, most of them parabolic, but today they present cliffs resulting from coastal erosion. In the southern part of the study area, dune systems are significantly enlarged (Coelho et al. 2009) and include foredunes, parabolic dunes, transverse dunes, and dunes with podzols.

Diversity and biogeography of sand-dune vegetation in northern Portugal have also been established in previous surveys documenting the transitional biogeographic char-

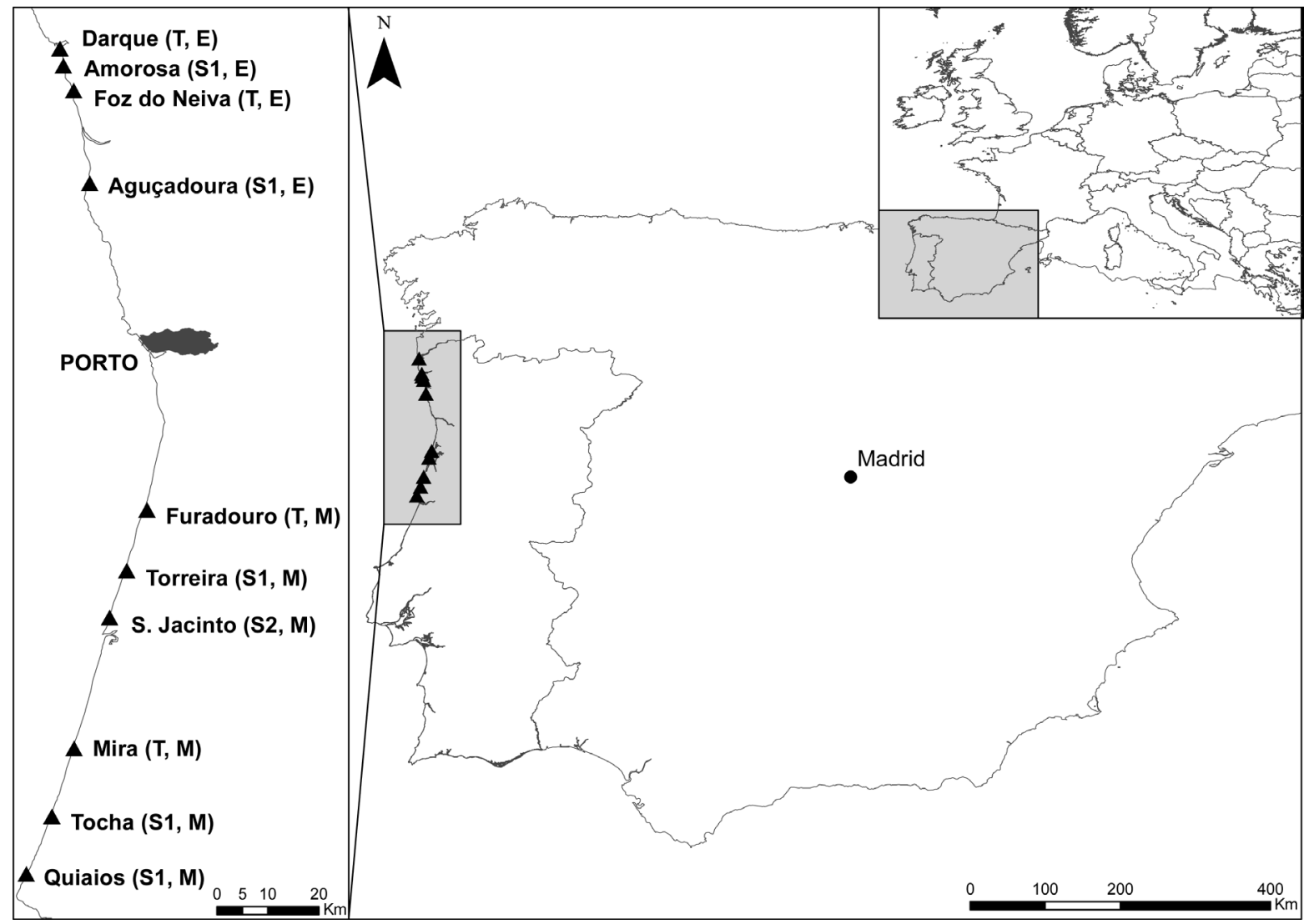

Figure 1. Location of the studied area in the Iberian and European contexts (right), with sampling sites indicated along the coastline (left). Prevailing dynamics (S1: (meta-) stable; S2: progradant; T: transgressive) and biogeographic location (E: Eurosiberian; M: Mediterranean) are indicated for each site. 
acter of this coastal area, which includes the westernmost transition between the Eurosiberian and Mediterranean biogeographic regions (Rivas-Martínez et al. 2002, Lomba et al. 2006, 2008). Dune vegetation exhibits a mixture of temperate Atlantic (Eurosiberian) and Mediterranean floristic elements, with the latter becoming dominant towards south. Three major perennial vegetation types typically occur as parallel strands, with sand-couch (Elytrigia juncea ssp. boreatlantica) vegetation colonizing embryonic foredunes, marram (Ammophila arenaria ssp. arundinacea) formations dominating foredune tops, and dwarf-shrub vegetation of Artemisia crithmifolia, Crucianella maritima and Helichrysum italicum ssp. picardi, colonizing interior dunes.

\section{Field surveys (dataset collection)}

Sampling sites were selected and classified on the basis of previous studies documenting the dominant dynamic behaviour (Granja and Carvalho 1992, Granja 1997, Loureiro and Granja 2001), complemented with field observations at the time of site selection. This way, 10 sites were selected which spread throughout the study area and exhibited prevailing (meta-) stable, transgressive (erosive or in recession) or progradant (with sediment accretion) coastal dynamics (Fig. 1).

At each site, a station point was established and georeferenced using a GPS device. From this station point, all topographic profile points were obtained using a Leica TC 605 total station. Three parallel topographic profiles were obtained from each site, with a distance of $25 \mathrm{~m}$ between each two profiles. Profiles were recorded from the water line to the highest foredune top (or 'frontal dune', here considered as the first dune ridge, even if it was a paleo- dune facing the present beach due to recession), in a direction perpendicular to shoreline alignment. Because the final topographic datasets were limited to their vegetated sectors (below), water line variation was considered irrelevant for data collection. Moreover, because we focused on beach-foredune dynamics and collected data from dune systems with well developed interior dunes (devoid of strong human pressure), we also considered back dune characteristics of scarce relevance for our study.

Vegetation profiles were collected along topographic profiles by recording the relative frequency of plant species and of bare sand at $0.5 \mathrm{~m}$ intervals. At each point along the profile, relative frequencies (i.e. the number of point interceptions) of plant species (or bare sand) were recorded on $2 \mathrm{~m}$ long transepts perpendicular to profile direction. Nomenclature details and codes for plant taxa included in text, tables and figures are presented in Appendix 1.

\section{Datasets and statistical analyses}

Field surveys provided a vegetation dataset, consisting of plant species abundance (point frequency) along each of 30 profiles, and a topographic dataset, consisting of altitude variations along each profile. In order to allow comparability, final profiles (both topography and vegetation) used in statistical analyses started at the highest foredune top (crest) and ended at the beach-end of the vegetation profile. This way, comparable vegetation/topography profiles of the exposed face of the foredune system were obtained. From this combined dataset, synthetic metrics expressing the main topographic and vegetation features of profiles (Table 1) were calculated. Pair-wise correlations between metrics were assessed using Spearman's rho correlation.

Table 1. Quantitative attributes calculated for each vegetated profile from the topographic and vegetation datasets.

\begin{tabular}{ll}
\hline $\begin{array}{l}\text { Topography } \\
\text { Length }\end{array}$ & Surface distance $(\mathrm{m})$ between the two ends of the profile \\
Height & Vertical distance $(\mathrm{m})$ between the two ends of the profile \\
Slope & Mean slope $(\%)$ of the profile i.e. the height/length ratio \\
Complexity & $\begin{array}{l}\text { Topographic complexity of the profile, measured from the variance of height, divided by mean slope (to } \\
\text { discriminate variance values derived from actual complexity and those derived from steep slopes) }\end{array}$ \\
Vegetation & $\begin{array}{l}\text { Shannon diversity index } \\
\text { SHDI }\end{array}$ \\
SHEQ & $\begin{array}{l}\text { Shannon equitability index } \\
\text { \% bare }\end{array}$ \\
Gamma & $\begin{array}{l}\text { Total species richness of the profile } \\
\text { Beta \% of gamma explained by its additive beta component (i.e. the numerical difference between gamma and mean }\end{array}$ \\
E/A ratio & $\begin{array}{l}\text { Ratio between the relative abundance of Elytrigia boreoatlantica and Ammophila arundinacea (dominant species in } \\
\text { beach-foredune vegetation) }\end{array}$
\end{tabular}


Quantitative attributes of beach and dune morphology, such as width (or length), height, and slope, have been previously related to predominant coastal dynamics (Saye et al. 2005, Martínez et al. 2006) and were hence used here, together with topographic complexity, to characterize foredune profiles in the study area (Table 1). For simplicity and comparative purposes throughout the text, foredune profiles were 'classified' according to those four major features of their morphology. Four classes ('character states') were defined for each character, with cutting values between character states being obtained from scatter plots of values for the 30 profiles. This way, profiles ranged from 'very short' to 'very long' for profile length, from 'very low' to 'very high' for profile height, from 'very gentle' to 'very steep' for profile mean slope, and from 'very simple' to 'very complex' for topographic complexity. Statistical differences between geomorphologic features of profile groups were assessed for significance through one-way ANOVA complemented with unbalanced Tukey tests for pair-wise comparisons among means.

The vegetation dataset was analysed using multivariate statistics, aiming to address similarity among ecological responses of individual species and possible relations between floristic assemblages and topographic predictors. An independent ordination analysis of the vegetation dataset was first carried out by indirect gradient analysis (detrended correspondence analysis, or DCA), using default settings of Canoco for Windows (four re-scaling cycles and 26 segments to re-scaling, according to Hill's method) in order to analyse major distributional variation and inherent gradients in the data (Legendre and Legendre 1998, ter Braak and Smilauer 2002). The determined gradient length (1.8 SD) supported our selection of linear methods to perform posterior direct gradient analysis on species and environmental data (ter Braak and Smilauer 2002). Then, multi-variate redundancy analysis (RDA) was used to assess putative relations between species composition of the vegetation profiles and either diversity metrics or topographic attributes, using a forward selection approach (tested using the Monte Carlo permutation test, based on 499 random permutations) (ter Braak and Smilauer 2002).

Floristic diversity analyses were performed, using the additive partitioning approach of total (gamma) diversity into its alpha and beta components (Veech at el. 2002), in this case applied to species richness. With the purpose of obtaining additional insights on community assembly and response to disturbance, plant species were also classified in three major functional types, as described by García-Mora et al. (1999): perennials with strong adaptive syndromes to the dune environment ('type III'), perennials with moderate adaptation to dunes ('type II'), and ruderal annuals without dune-specific adaptive syndromes ('type I').

ANOVA tests and correlation analyses, and ordination analyses, were implemented in Statistica (StatSoft 2008) and Canoco for Windows, respectively.

\section{Results}

\section{Foredune topography and coastal dynamics}

The 30 sampled topographic profiles included important variations in all four topographic attributes (Table 2). Veg-

Table 2. Types (and subtypes) of profiles according to the four major topographic attributes assessed (length, height, slope, and complexity) and corresponding mean $( \pm \mathrm{SD})$ values.

\begin{tabular}{|c|c|c|c|c|}
\hline \multicolumn{2}{|c|}{ Profile types (subtypes) } & $\mathrm{T}(\mathrm{n}=12)$ & $\mathrm{S} 1(\mathrm{n}=15)$ & $\mathrm{S} 2(\mathrm{n}=3)$ \\
\hline \multicolumn{2}{|c|}{ Predominant local dynamics } & transgressive (erosion) & (meta-) stable & progradant (accretion) \\
\hline \multirow{8}{*}{ 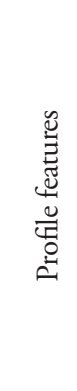 } & \multirow{2}{*}{ Height } & very-low to low & low to very-high & high \\
\hline & & $2.0 \pm 0.84$ & $6.2 \pm 1.7$ & $5.8 \pm 0.52$ \\
\hline & \multirow{2}{*}{ Length } & very-short & short to long & very-long \\
\hline & & $6.2 \pm 4.0$ & $33 \pm 14$ & $119 \pm 18$ \\
\hline & \multirow{2}{*}{ Slope } & very-steep to gentle & steep to gentle & very-gentle \\
\hline & & $41 \pm 15$ & $20 \pm 5.9$ & $4.9 \pm 0.35$ \\
\hline & \multirow{2}{*}{ Complexity } & very-simple to simple & simple to very-complex & simple to complex \\
\hline & & $0.016 \pm 0.013$ & $0.19 \pm 0.097$ & $0.36 \pm 0.21$ \\
\hline \multicolumn{2}{|l|}{ Sites } & $\begin{array}{l}\text { Darque } \\
\text { F. Neiva } \\
\text { Furadouro } \\
\text { Mira }\end{array}$ & $\begin{array}{l}\text { Aguçadoura } \\
\text { Amorosa } \\
\text { Quiaios } \\
\text { Tocha } \\
\text { Torreira }\end{array}$ & São Jacinto \\
\hline
\end{tabular}


etated profile length ranged from $1.4 \mathrm{~m}$ in Mira (very short, transgressive profile) to $138 \mathrm{~m}$ in the very long, progradant profiles of São Jacinto, whereas height varied from less than a meter $(0.81 \mathrm{~m})$ in the very low vegetated profiles of Mira to $8.7 \mathrm{~m}$ in the very high (meta-) stable profiles of Tocha. The observed range for slope was from $4.5 \%$ in the very gentle profiles of São Jacinto to $62 \%$ in the very steep, transgressive profiles of Furadouro, and the complexity ratio varied from 0.002 in Mira (very simple profile) to 0.60 in São Jacinto (very complex profile). All four attributes were found to be correlated ( $p<0.01)$ and can thus be considered mutual surrogates. In our study area, longer profiles tend to be higher, globally gentler (i.e. with lower mean slope) and topographically more complex than shorter profiles. The mean values of profile length, height, slope and complexity for the two major groups of profiles - transgressive $(\mathrm{T})$ and stable $(\mathrm{S})$ - were confirmed as significantly different, as demonstrated by one-way ANOVA $(p<0.05)$. When segregating (meta-) stable (S1) and progradant (S2) profiles, Tukey tests $(\mathrm{p}<$ 0.05 ) revealed that profile length is significantly different among the three groups (T, S1 and S2).

The close relationship between foredune topography and prevailing local dynamics thus supported the previous discrimination of the two major types of profiles ( $\mathrm{S}$ and $\mathrm{T}$; Table 2, Fig. 2). Transgressive profiles (T) are characteristically very-short and (very-) low, with vegetation covering small altitude ranges; slope and complexity are variable, though there is a tendency towards steep and simple profiles. The second major group $(S)$ includes profiles exhibiting either (meta-) stable or progradant dynamics. Profiles of (meta-) stable coastal areas (S1) are mostly defined by their high topographic complexity i.e. there is a clear discrimination between geoforms, with embryonic foredunes and foredunes well recognisable as individual geomorphologic features. Profiles exhibiting progradant dynamics (S2) are longer and gentler, with multiple parallel strands of both embryonic foredunes and foredune crests.

\section{Vegetation assembly, dune topography, and coastal dynamics}

\section{General compositional patterns}

Throughout the 30 foredune profiles, only Elytrigia boreoatlantica and Ammophila arundinacea, two rhizomatous perennial grasses, were found to be dominant (in terms of their relative abundance) in any given sector of vegetated profiles (Fig. 3). In (meta-) stable profiles (S1; Fig. 3a), formations dominated by Elytrigia or Ammophila tend to occupy specific positions (strands) in embryonic foredunes and in foredune crests, respectively. Progradant profiles (S2) tend to exhibit similar vegetation patterns, though there may be multiple parallel Elytrigia and/or Ammophila dominated strands related to high topographic complexity. This discrimination of vegetation types along the gradient is confirmed by the high mean values of the additive beta component of plant species richness that characterize (meta-) stable (74\% of total profile species richness) and progradant $(93 \%)$ profiles in the area. On the contrary, in transgressive $(\mathrm{T})$ dune systems, species of both vegetation types tend to coexist and to replace each other gradually along the disturbed topographic profile (Fig. 3b). This 'vegetation continuum' is well indicated by the lower mean value of additive beta richness (60\%) which characterizes transgressive profiles in the area. Nonetheless, values for additive beta richness from the 30 vegetation profiles were found to plot logarithmically against profile length (Fig. 4), the best topographic indicator of profile stability (cf. Table 2), suggesting that additive beta-richness may only exhibit a sharp decrease under extreme disturbance conditions.

A cluster analysis of the 29 plant taxa according to their occurrence throughout the 30 vegetation profiles discriminated the nine taxa with the highest frequencies in the dataset (occurring in more than $1 / 3$ of the profiles) from those with lower frequencies (casuals). Among those nine taxa, Crucianella maritima, Euphorbia paralias and Otan-

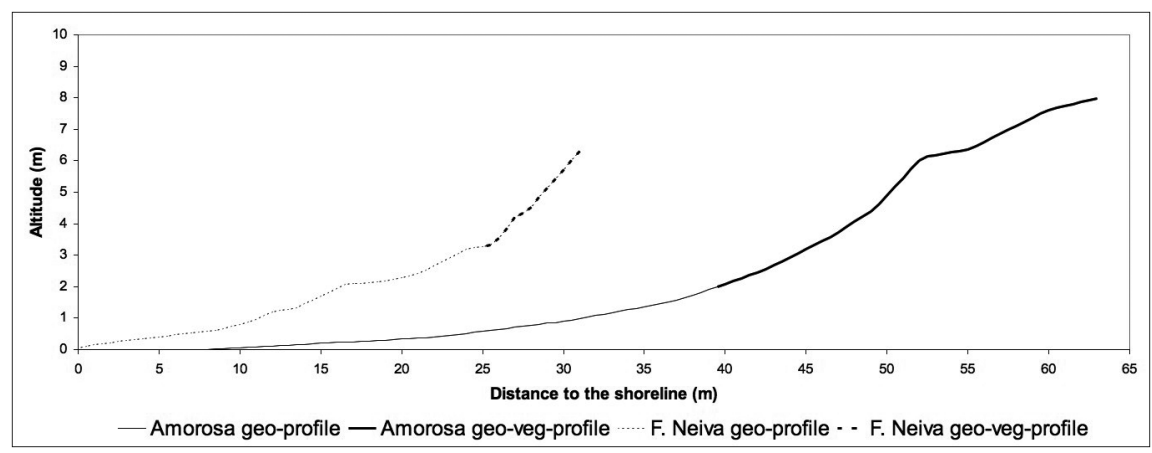

Figure 2. Indicative topographic profiles of sites with transgressive (F. Neiva, dashed lines) and (meta-) stable (Amorosa, solid lines) dynamics. Thick lines indicate the extension of vegetated profiles, from which all data used in statistical analyses were collected. 

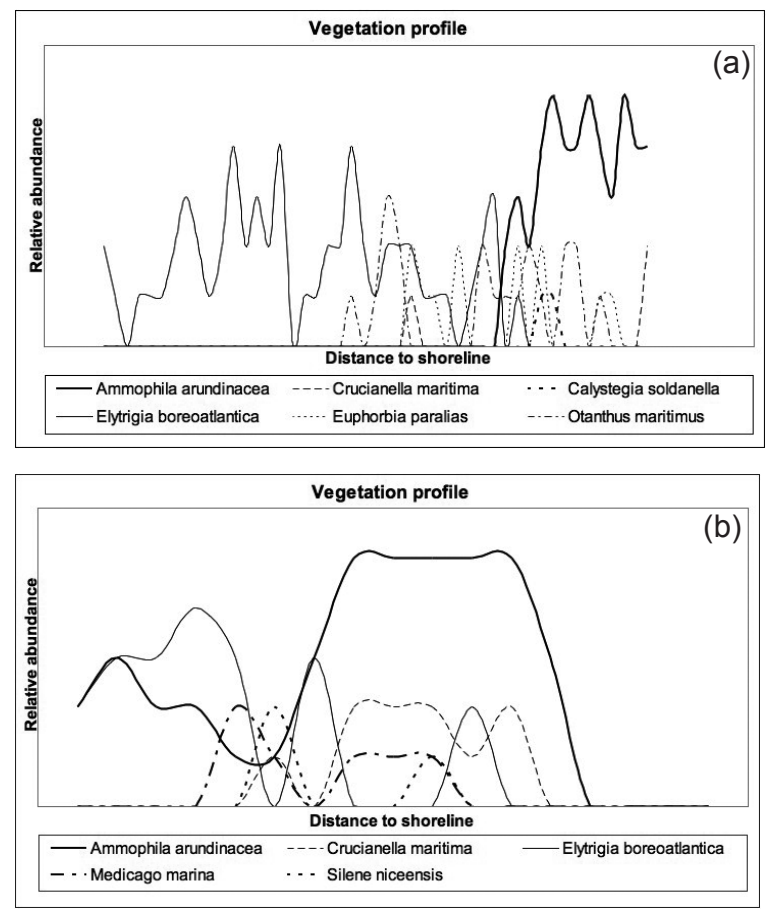

Figure 3. (a) typical vegetation profile of a (meta-) stable site ('S1') of the northern Portuguese coastline (Quiaios). Notice the clear floristic discrimination between Elytrigia-dominated vegetation of embryonic foredunes (left) and Ammophila-dominated formations of foredune crests (right). Mean point species richness along the profile is 1.51 . (b) typical vegetation profile of a transgressive site ('T'; Foz do Neiva site). Notice the continuum between Elytrigia-dominated vegetation of embryonic foredunes and Ammophila-dominated formations of foredunes, with $\mathrm{Am}$ mophila arundinacea, Elytrigia boreoatlantica and other species occurring throughout the vegetation profile (indicating more homogeneous environmental conditions). Mean point species richness along the profile is 2.24 .

thus maritimus were found to be the ones exhibiting the most discriminating responses, with clear preference for (meta-) stable and progradant profiles (Fig. 5). Correlation analyses between diversity measures (cf. Table 1) and the relative abundances (\% of total point occurrences) of those nine taxa revealed that there is a general tendency for strong positive correlations among floristic attributes of dune vegetation (Table 3). The only important exception is the relative abundance of Ammophila arundinacea $(\% \mathrm{Aa})$, which is negatively correlated to most other measures. Significant correlations were also found among diversity statistics (i.e. the Shannon diversity and equitability indices, gamma richness, and additive beta richness), indicating mutual surrogacy among metrics which express distinct community features of vegetation profiles.

\section{Community composition and diversity measures}

Redundancy analysis showed that $99 \%$ of the total variability in the vegetation dataset is accurately synthesized by

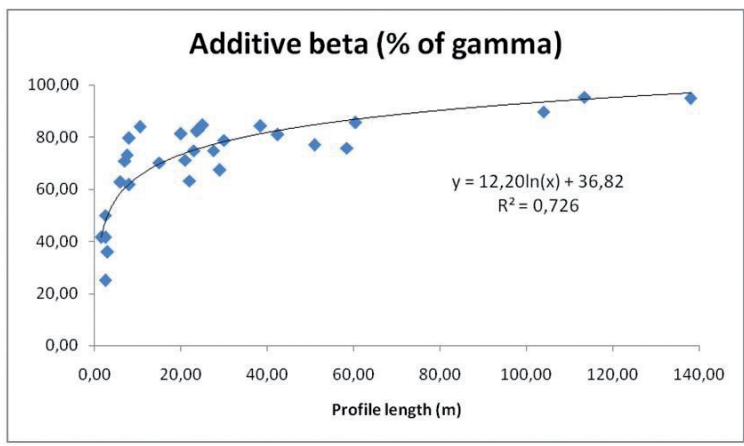

Figure 4. Logarithmic relation between the additive beta component of species richness and vegetated profile length, a measure of stability in foredunes.

the considered set of diversity metrics (cf. Table 1). Moreover, the first two RDA axes present a considerable contribution, as they account for ca $83 \%$ of total variability (eigenvalues: RDA 1-0.70, RDA 2-0.13, RDA 3-0.07, RDA 4-0.050). In the ordination diagram of Fig. 6, the relations between the floristic composition of the profiles and diversity metrics are assessed. The first axis $(70 \%$ of total variability) depicts a dominant gradient highly correlated to the relative abundance of Ammophila arundinacea (\% Aa; $\mathrm{R}=0.99$ ), which was identified as significantly contributing to the model $(\mathrm{F}=61, \mathrm{p}=0.0020)$. The relative abundance of Elytrigia boreoatlantica (\% Eb; F = 35, p $=0.002)$ also provided a statistically significant contribution for the model, exhibiting, together with the E/A ratio, negative correlations with the first axis (\% $\mathrm{Eb}: \mathrm{R}=-0.86$, $\mathrm{E} / \mathrm{A}: \mathrm{R}=-0.67$ ), confirming results from correlation analyses among metrics (cf. Table 3). The second RDA axis depicts a gradient related to the relative abundance of $A r-$

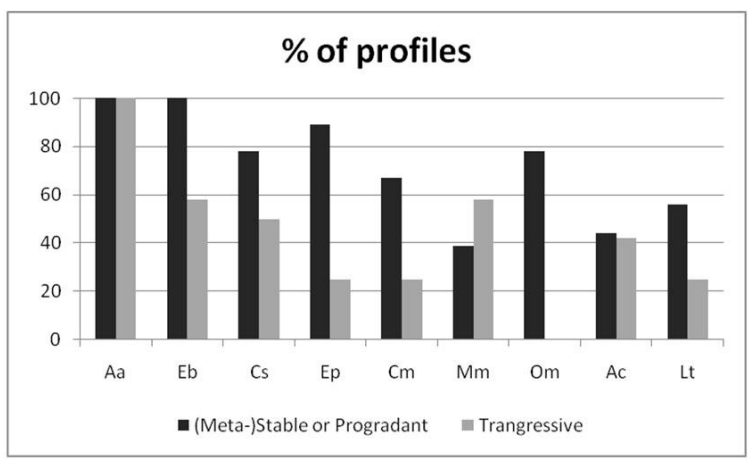

Figure 5. Occurrence of the nine most frequent taxa in the dataset, computed as the percentage of profiles of each major profile type $(\mathrm{S}$ and $\mathrm{T})$ in which each species was recorded. Notice how the general tendency of species to occur preferably in (meta-) stable/progradant profiles is clearly enhanced in the case of $E u$ phorbia paralias (Ep), Crucianella maritima $(\mathrm{Cm})$ and Otanthus maritimus (Om). Plant taxa (see Appendix 1 for codes) are ordered, from left to right, according to their global frequency in the dataset. 
Table 3. Correlations (Spearman's rho) among vegetation attributes of the 30 profiles. Notice the general pattern of positive correlations between variables, except in the case of relative abundance of Ammophila arundinacea. $\left({ }^{* *}\right)=\mathrm{p}<0.01,\left({ }^{*}\right)=\mathrm{p}<0.05$.

\begin{tabular}{|c|c|c|c|c|c|c|}
\hline & $\underset{\sim}{\stackrel{\vec{D}}{\mid}}$ & $\begin{array}{l}\text { O } \\
\text { 至 } \\
\text { 忈 }\end{array}$ & $\frac{\tilde{\Xi}}{\frac{0}{2}}$ & 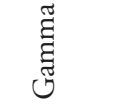 & 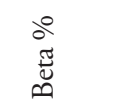 & $\underset{\text { 出 }}{ }$ \\
\hline$\% \mathrm{Aa}$ & $-0.59\left(^{(* *}\right)$ & -0.29 & -0.24 & $\left.-0.70{ }^{(* *}\right)$ & $\left.-0.511^{* *}\right)$ & $-0.94(* *)$ \\
\hline$\%$ Ac & $0.42\left(^{*}\right)$ & 0.24 & -0.31 & $0.46\left(^{*}\right)$ & 0.088 & 0.11 \\
\hline$\% \mathrm{Cm}$ & $0.80(* *)$ & $0.66\left(^{* *}\right)$ & 0.31 & $\left.0.79^{(* *}\right)$ & $0.74(* *)$ & $0.39\left(^{*}\right)$ \\
\hline$\% \mathrm{Cs}$ & -0.18 & -0.13 & $0.45\left(^{*}\right)$ & -0.19 & -0.012 & 0.21 \\
\hline$\% \mathrm{~Eb}$ & 0.31 & 0.052 & 0.30 & $\left.0.48{ }^{* *}\right)$ & $0.40\left(^{*}\right)$ & $0.96\left(^{* *}\right)$ \\
\hline$\%$ Ep & $0.47\left(^{* *}\right)$ & $0.45\left(^{*}\right)$ & 0.23 & $0.46\left(^{*}\right)$ & $0.51\left(^{* *}\right)$ & $0.47\left(^{* *}\right)$ \\
\hline$\% \mathrm{Lt}$ & $0.41\left(^{*}\right)$ & 0.36 & $0.47\left(^{* *}\right)$ & $0.36\left(^{*}\right)$ & $0.46\left(^{*}\right)$ & 0.21 \\
\hline$\% \mathrm{Mm}$ & 0.28 & 0.29 & -0.30 & 0.26 & -0.087 & 0.041 \\
\hline$\% \mathrm{Om}$ & $0.62\left(^{* *}\right)$ & $\left.0.48{ }^{(* *}\right)$ & $0.46\left(^{*}\right)$ & $0.60\left(^{* *}\right)$ & $0.65\left(^{* *}\right)$ & $0.55\left(^{* *}\right)$ \\
\hline
\end{tabular}

temisia crithmifolia $(\mathrm{R}=0.88)$, Calystegia soldanella $(\mathrm{R}=$ $-0.61)$, and Medicago marina $(\mathrm{R}=0.48)$. Together with those in Table 3, these results suggest that the first RDA axis is related to community variations driven by local environmental gradients, whereas the discriminative regular occurrence of Artemisia crithmifolia in foredune vegetation of the northern (i.e. Eurosiberian) profiles suggests that the second axis most likely depicts biogeographic effects and/ or regionally structured gradients.

\section{Community assembly and dune topography}

Compositional features of vegetation profiles were compared to variations in the four major topographic attributes through RDA. From the $57 \%$ of total variability in floris-

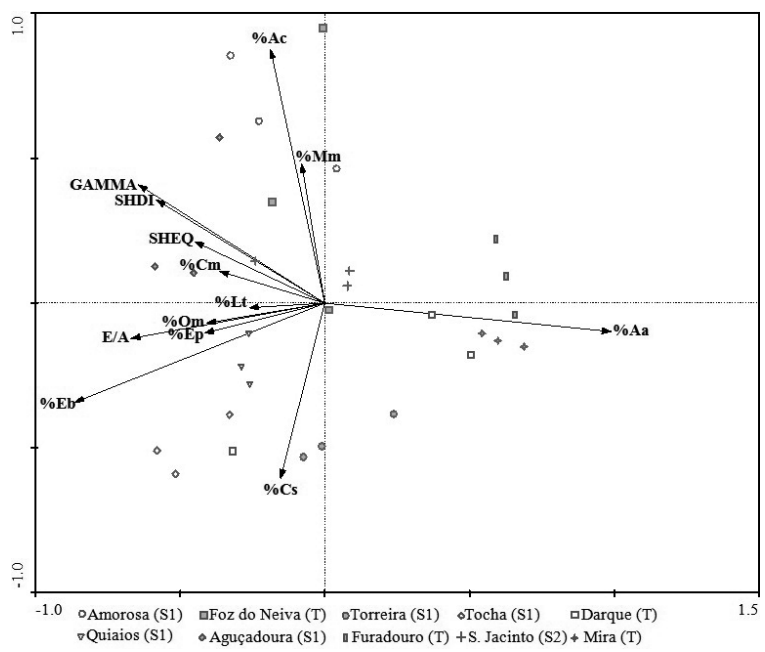

Figure 6. Redundancy analysis (RDA) diagram of vegetation profiles, with quantitative attributes of diversity represented on the ordination space (see Table 1 for codes of diversity attributes and Appendix 1 for codes of plant taxa). tic patterns explained by the model, ca $49 \%$ are explained by the first axis, with the other three exhibiting very low contributions (eigenvalues RDA 1-0.49, RDA 2-0.05, RDA 3-0.03, RDA 4-0.004). The first axis was found to be strongly correlated to profile height $(R=-0.80)$, slope $(\mathrm{R}=0.64)$, and complexity $(\mathrm{R}=-0.77)$, whereas a subtle gradient of profile length is underlying the second axis. Moreover, profile height $(\mathrm{F}=21, \mathrm{p}=0.002)$, slope $(\mathrm{F}=$ 3.9, $\mathrm{p}=0.010)$ and length $(\mathrm{F}=3.7, \mathrm{p}=0.02)$ had statistically significant contributions to the model. Correlation analyses between floristic attributes of vegetation and topographic features collected from the 30 profiles ( $\mathrm{Ta}$ ble 4) revealed that profile length, height and complexity are positively correlated to most floristic metrics, whereas profile slope exhibits an inverse pattern. The major exception from the vegetation dataset is once again the relative abundance of Ammophila arundinacea, which presents an opposite correlation pattern to all other metrics. Also, the relative abundances of Ammophila arundinacea, Elytrigia boreoatlantica and Otanthus maritimus are the floristic metrics exhibiting the strongest correlations to all four topographic features.

\section{Plant functional types and coastal dynamics}

In Fig. 7, the occurrence of the whole species pool is compared among profiles differing in local dynamics and biogeographic location, with species classified into dune plant functional types as described by García-Mora et al. (1999). This analysis revealed that: 1) (meta-) stable/progradant profiles ('S') are richer than transgressive profiles ('T'), for total species richness and for individual functional types; 2) northern (i.e. Eurosiberian) profiles are richer than their southern (Mediterranean) counterparts, for total species richness and for individual functional types; 3 ) foredune specialists (type III species) are dominant under any combination of environmental conditions, nevertheless they 
Table 4. Correlations (Spearman's rho) between topographic and vegetation attributes of the 30 profiles. (See Table 1 for codes and attributes and Appendix 1 for codes of plant taxa.). $\left(^{* *}\right)=p$ $<0.01,\left({ }^{*}\right)=\mathrm{p}<0.05$.

\begin{tabular}{|c|c|c|c|c|}
\hline & Length & Height & Slope & Complexity \\
\hline \multicolumn{5}{|c|}{ Synthetic metrics for vegetation profiles } \\
\hline SHDI & $0.67\left(^{* *}\right)$ & $0.66(* *)$ & $-0.44\left(^{*}\right)$ & $0.70\left(^{* *}\right)$ \\
\hline SHEQ & $0.38\left(^{*}\right)$ & 0.32 & -0.27 & $0.38\left(^{*}\right)$ \\
\hline$\%$ bare & $0.60\left(^{* *}\right)$ & $0.37\left(^{*}\right)$ & $-0.69\left(^{* *}\right)$ & $0.51(* *)$ \\
\hline Gamma & $0.74(* *)$ & $0.80(* *)$ & $-0.48\left(^{* *}\right)$ & $0.79\left(^{* *}\right)$ \\
\hline Beta $\%$ & $0.79\left(^{* *}\right)$ & $0.73(* *)$ & $-0.59\left(^{* *}\right)$ & $0.80\left(^{* *}\right)$ \\
\hline E/A ratio & $0.67(* *)$ & $0.77(* *)$ & $-0.54(* *)$ & $0.73(* *)$ \\
\hline \multicolumn{5}{|c|}{ Relative abundance of individual species } \\
\hline$\% \mathrm{Aa}$ & $-0.69\left(^{* *}\right)$ & $\left.-0.80{ }^{* *}\right)$ & $0.51(* *)$ & $-0.76(* *)$ \\
\hline$\%$ Ac & 0.0060 & 0.26 & 0.31 & 0.11 \\
\hline$\% \mathrm{Cm}$ & $0.48(* *)$ & $0.50(* *)$ & -0.25 & $0.52(* *)$ \\
\hline$\% \mathrm{Cs}$ & 0.19 & 0.0040 & $-0.51(* *)$ & 0.13 \\
\hline$\% \mathrm{~Eb}$ & $0.58\left(^{* *}\right)$ & $0.66\left(^{* *}\right)$ & $-0.53\left(^{* *}\right)$ & $0.64\left({ }^{* *}\right)$ \\
\hline$\%$ Ep & $0.45\left(^{*}\right)$ & $0.57\left(^{* *}\right)$ & -0.29 & $0.52(* *)$ \\
\hline$\% \mathrm{Lt}$ & $0.41\left(^{*}\right)$ & 0.21 & $\left.-0.47^{* *}\right)$ & $0.38\left(^{*}\right)$ \\
\hline$\% \mathrm{Mm}$ & -0.22 & -0.030 & 0.31 & -0.14 \\
\hline$\% \mathrm{Om}$ & $0.74(* *)$ & $0.61(* *)$ & $-0.60\left(^{* *}\right)$ & $0.73(* *)$ \\
\hline
\end{tabular}

are severely impacted by increased disturbance related to transgressive dynamics, particularly in Mediterranean areas; and 4) ruderals (type I species) are regularly present in Eurosiberian foredunes, where they are moderately impacted by transgressive dynamics, whereas in Mediterranean areas they are rare under (meta-) stable/progradant conditions and completely absent from transgressive profiles.

\section{Discussion}

\section{Can synthetic quantitative attributes of topographic profiles be used as indicators of predominant local dynamics?}

The close relation between geomorphology and short-term coastal dynamics (Andrade and Ferreira 2006, Levin et al. 2006) stresses the importance of quantitative topographic studies of dune profiles to identify precise indicators, to predict future trends and to define management actions (Saye et al. 2005). In our study of foredune ecosystems, values for a number of quantitative attributes expressing distinct features of dune topography (length, height, slope, and complexity) were obtained from field recorded veg- etated topographic profiles. We found a general tendency for correlation (surrogacy) among those attributes, which may prove to be most useful for the regular collection of topographic data (e.g. in the context of environmental surveillance or monitoring), considering that measuring some of them (e.g. vegetated profile length) does not actually require the time-consuming collection of detailed topographic profiles.

Even though historical datasets from which to derive coastal modification rates are scarce, indicators relating geomorphology to coastal dynamics (e.g. the high water line, the foredune vegetation line) have been previously combined with field observations in the Portuguese coastline to classify some coastal sectors as transgressive, (meta-) stable or progradant (Henriques 2007, cf. Fig. 1). In our study, these three types of dynamic situations were statistically discriminated based on the combined values of the four assessed topographic features (cf. Table 2). Thus, vegetated sectors of transgressive profiles are typically short and low, with a tendency for steep and simple morphologies, whereas the typical profiles of (meta-) stable coastal areas usually exhibit high topographic complexity, with progradant profiles being globally similar but usually longer and gentler. Overall, our results confirm that changes in prevailing coastal dynamics induce specific modifications in dune geomorphology (Saye et al. 2005, et al. 2006), and that simple, standard quantitative attributes can be used to evaluate and monitor those changes. In this regard, profile length was found to be the topographic feature of vegetated profiles with the highest diagnostic character (cf. Table 2), suggesting that a cost-efficient methodology for the surveillance and monitoring of coastal dynamics might include simple measurements of vegetated profile length in combination with bioindicators provided by studies of vegetation assembly and dynamics.

\section{Which features of foredune vegetation are most influenced by variations in topography, and how is local vegetation response to those variations influenced by regional gradients?}

Using functional approaches to assess dune vegetation assembly and dynamics, García-Mora et al. (1999) and Feagin and Wu (2007) highlighted geomorphology and sediment mobility as major drivers of community assembly in coastal sand dune ecosystems submitted to frequent disturbance. Confirming those reports, our results demonstrate that the typical discrimination of embryonic foredune Elytrigia stands and foredune top Ammophila formations in sites with (meta-) stable dynamics is disrupted and transformed into a vegetation continuum by topographic changes in foredunes under transgressive dynamics (cf. Fig. 3 ), suggesting that species turnover metrics such as additive beta richness may act as reliable indicators of transgressive disturbance in foredune vegetation (cf. Fig. 4). 


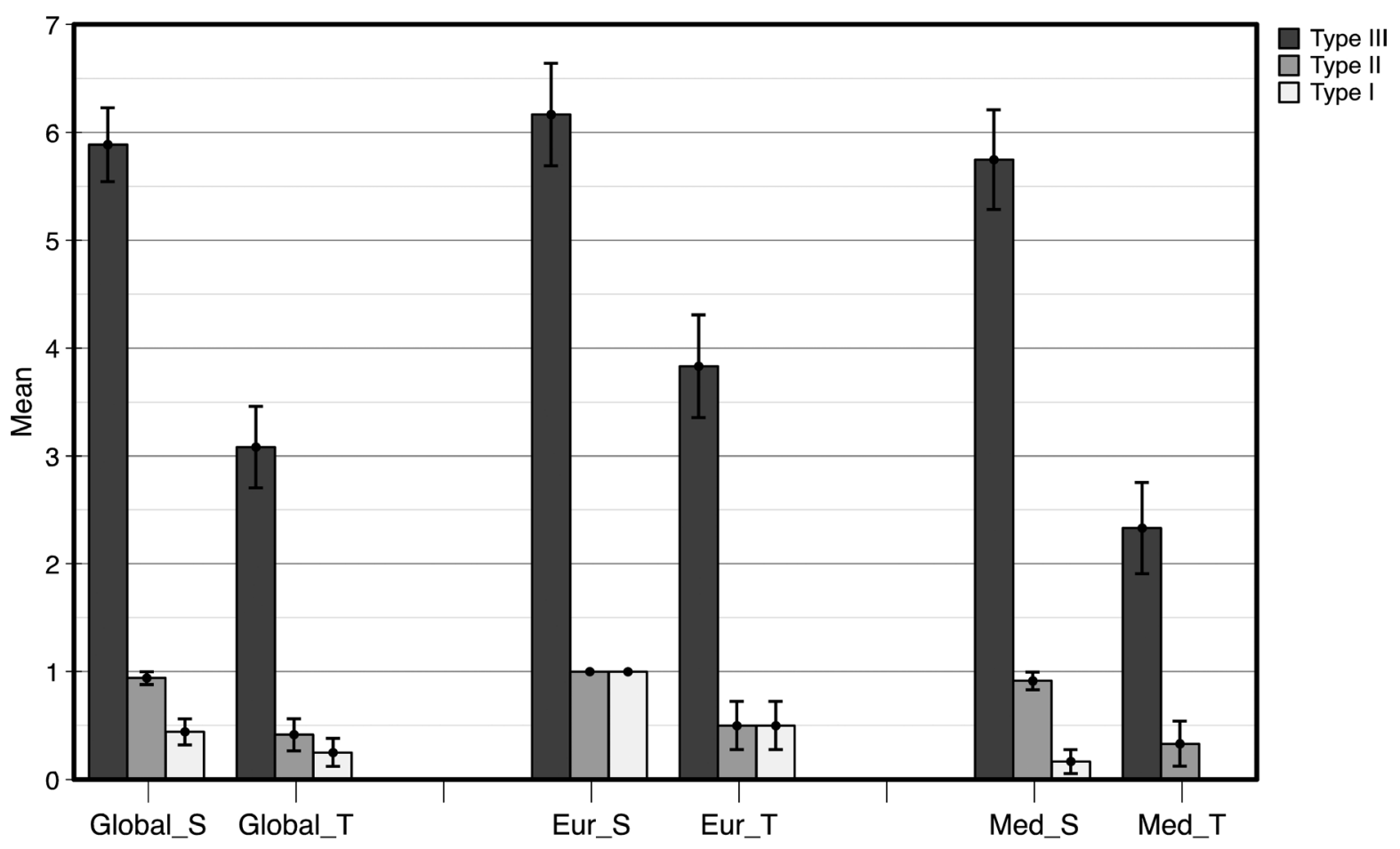

Figure 7. Mean number of species (and corresponding standard error bars) belonging to functional types I, II and III of García-Mora et al. (1999) in type $S$ and type T dune profiles, for the overall dataset ('Global'), in Eurosiberian areas ('Eur') and in Mediterranean areas ('Med').

The correlations between the four topographic features of profiles and the vegetation RDA axes further confirmed that dune topography plays an important role in determining the assembly of foredune vegetation (García-Mora et al. 1999, Feagin and Wu 2007). Moreover, correlation analyses confirmed that topographic features exhibited significant correlations with several community measures e.g. the Shannon diversity index, the percentage of bare sand, total (gamma) species richness and its beta additive component, the relative abundance of Otanthus maritimus, Elytrigia boreoatlantica and Ammophila arundinacea (three foredune species according to Rivas-Martínez et al. 2002), and the ratio between the abundances of the two later species (cf. Table 4). The values of all these metrics (except the relative abundance of Ammophila) were found to decrease under transgressive dynamics, indicating that such increased disturbance produces Ammophila-dominated vegetation profiles with fewer species, increased dominance, lower turnover rates, and lower total vegetation cover. These changes may drive a decrease in structural and functional diversity, with important consequences for resistance, resilience and other ecosystem properties (García-Mora et al. 1999, Feagin and Wu 2007, Lortie and Cushman 2007).

Results for Otanthus maritimus, Elytrigia boreoatlantica and Ammophila arundinacea confirm those from previous studies reporting the connection between the occur- rence of one or more of these species and coastal dynamics (Corre 1991, Mayoral and Gómez-Serrano 2002). Particularly, the presence of Otanthus maritimus seems to be a reliable indication of foredune stability since this species has been reported to be sensitive to changes in the dune structure (Mayoral and Gómez-Serrano 2002). In transgressive profiles, Ammophila arundinacea becomes an absolute dominant, not only because of its capability to survive deep sand burial (García-Mora et al. 1999, Levin et al. 2008), but also due to the reduction or disappearance of other species (as indicated by its negative correlation to other biological metrics; cf. Table 3), possibly due to loss of facilitation efficiency under extreme stress conditions (Brooker et al. 2008).

Highlighting the peculiar nature of vegetation assembly in coastal environments (Dech and Maun 2005, Feagin et al. 2005b, Lortie and Cushman 2007), multi-variate statistics (RDA) revealed that local ecological conditions relatable to coastal dynamics accounted for $70 \%$ of the variations among vegetation profiles, with most synthetic biological metrics exhibiting strong correlations to the first RDA-axis. Biogeographic effects (related to the contact between two biogeographic regions) and regionally structured gradients, associated to the second RDA-axis, thus seem to be of less importance in the structuring of vegetation profiles. However, compositional differences driven by biogeography are not negligible (cf. Fig. 6), confirming 
that foredune vegetation assembly is also filtered by regional-scale controls (Forey et al. 2008) and that distinct sets of indicators may have to be used to discriminate between dynamic situations according to biogeographic context.

Our preliminary functional analysis of vegetation profiles, based on a limited number of dune-plant functional types (García-Mora et al. 1999), further confirmed that there are differences in dune vegetation assembly and response to changes in coastal dynamics between profiles in distinct biogeographic contexts (Fig. 7), even though only a residual percentage (3\%) of the compositional variation in the vegetation dataset was found to be due to interactions between biogeography and local dynamics. Nonetheless, even along our narrow biogeographic gradient (ca $200 \mathrm{~km}$ long), a decrease in facilitation efficiency under extreme stress conditions (Brooker et al. 2008) may be involved in the loss of unspecialized plants ('type I' species of GarcíaMora et al. 1999) related to both biogeography (i.e. water stress gradient due to southwards decreasing rainfall; Forey et al. 2008) and local dynamics (i.e. disturbance frequency and severity) (cf. Fig. 7).

\section{Can cost-efficient indicators of prevailing coastal dynamics be derived from fine-scale vegetation-topography assessments?}

There is an increasing demand of indicators for environmental reporting, planning, management and monitoring (Nimeijer and de Groot 2008), and coastal areas are among those which require urgent attention due to the severity of reported and forecasted impacts of environmental changes (Feagin et al. 2005a, Christian and Mazzilli 2007). The close relationship between coastal dynamics and dune vegetation assembly has been stressed as a promising source of indicators, particularly in the case of exposed foredune ecosystems (García-Mora et al. 1999, Lomba et al. 2008). Our results highlight that diversity measures such as the Shannon diversity index, total (gamma) species richness and its beta additive component, or compositional features such as the relative abundances of certain species and functional types in the vegetated profile, could well provide a reliable biological contribution for a coastal surveillance and monitoring protocol due to their strong connection to geomorphology and local dynamics.

An important caveat could be the fact that most of those potential bioindicators of coastal dynamics are rather time consuming and require the technical expertise to perform fine-scale vegetation assessments, two features regarded as disadvantageous in the process of indicator selection (Niemeijer and de Groot 2008). However, our results also suggest that fine-scale studies of vegetationtopography relations may actually provide cost-efficient indicators for surveillance and monitoring, since a number of species with adaptive syndromes related to foredune ecology ('type III' species sensu García-Mora et al. 1999) and usually considered typical foredune species (Mayoral and Gómez-Serrano 2002, Rivas-Martínez et al. 2002) e.g. Euphorbia paralias, Otanthus maritimus, Eryngium maritimum and Pancratium maritimum, were found to exhibit clear preference for (meta-) stable and progradant profiles (cf. Fig. 5). Moreover, the relative abundances of Euphorbia paralias and Otanthus maritimus in our dataset exhibit important correlations to other indicators concerning both vegetation (cf. Table 3) and topography (cf. Table 4). Overall, these results support the idea that the ratios between the frequencies of distinct plant functional types may be used to assess foredune dynamics (García-Mora et al. 1999). They further suggest that the simultaneous occurrence of a set of highly adapted species (the 'type III' species of García-Mora et al. 1999) in foredune vegetation profiles may be considered a surrogate of more complex and labour demanding bioindicators, providing, together with vegetated profile length, the foundations for cost-efficient diagnostic tools and monitoring protocols. However, such attractive possibility needs further evaluation through specific studies over wider biogeographic ranges, aimed at selecting the most appropriate indicator sets (Niemeijer and de Groot 2008).

\section{Conclusions}

Our results provide further support to the idea that assessments of the fine-scale arrangement of plant species along gradients in coastal sand dune vegetation can provide important insights on the processes involved in community assembly under severe stress and/or increased disturbance (Forey et al. 2008). Specifically, our study provided evidence of the close connection between dune topography and vegetation, thus relating dune vegetation to coastal dynamics (García-Mora et al. 1999, Feagin and Wu 2007). In fact, our compared analysis of the impacts of increased disturbance on quantitative features of ecosystems already characterized by heavy environmental stress supports the idea that different ecological filters of community assembly interact to determine compositional and dynamical features of foredune vegetation in a regional context (Forey et al. 2008).

However, even though our results highlight the large potential of fine-scale vegetation studies to provide costefficient indicators for monitoring coastal dynamics, longterm monitoring studies are needed to test and validate those putative indicators. First, historical data documenting coastal dynamics (from geomorphology and sediment transfer to geochemistry and vegetation assembly) are scarce and so actual causality is hard to establish. Secondly, even though our study included a major biogeographic transition and the results are congruent with those from more southern areas (García-Mora et al. 1999), the fact that differences in vegetation assembly and response to disturbance were found between Eurosiberian and Medi- 
terranean profiles stresses a possible biogeographic bias in the accuracy of bioindicators, even when plant functional types (instead of individual species) are considered.

The possible role of plant species and functional types as reliable and widely usable indicators of coastal dynamics should thus be further evaluated in studies over broad biogeographic ranges, exploring the role of such important processes as facilitation in filtering foredune vegetation assembly under projected shifts in climate and local dynamics (Bruno et al. 2003, Brooker et al. 2008, Forey et al. 2008). Due to the close connection between geomorphology and vegetation in sand dune ecosystems, confirmed by our results, those studies will surely provide cost-efficient sets of indicators to support monitoring processes to be implemented by technicians with basic ecological training. Results from such studies may also prove useful in other modern coastal management issues, namely in restoring degraded dune systems on sound ecological grounds (Freestone and Nordstrom 2001, Rozé and Lemauviel 2004, Nordstrom et al 2007), and in forecasting, monitoring and even adapting to impacts of global environmental changes on coastal areas (Feagin et al. 2005a, Lortie and Cushman 2007).

Acknowledgements - This research was funded by the Portuguese Science and Technology Foundation (FCT) through grant POCI/AMB/58047/2004. A. Lomba is supported by the Portuguese Science and Technology Foundation (FCT) through PhD grant SFRH/BD/31576/2006. J. Vicente is supported by the Portuguese Science and Technology Foundation (FCT) through $\mathrm{PhD}$ grant SFRH/BD/40668/2007. The authors would like to thank Cristiana Vieira, Helena Hespanhol and Joana Marques for comments on the manuscript.

\section{References}

Acosta, A. et al. 2005. Combining land cover mapping of coastal dunes with vegetation analysis. - Appl. Veg. Sci. 8: 133-138.

Adger, W. N. et al. 2005. Social-ecological resilience to coastal disasters. - Science 309: 1036-1039.

Andrade, F. and Ferreira, M. A. 2006. A simple method of measuring beach profiles. - J. Coastal Res. 22: 995-999.

Baas, A. C. W. 2007. Complex systems in aeolian geomorphology. - Geomorphology 91: 311-331.

Baas, A. C. W. and Nield, J. M. 2007. Modelling vegetated dune landscapes. - Geophys. Res. Lett. 34, L06405.

Brooker et al. 2008. Facilitation in plant communities: the past, the present, and the future. - J. Ecol. 96: 18-34.

Bruno, J. F. et al. 2003. Inclusion of facilitation into ecological theory. - Trends Ecol. Evol. 18: 119-125.

Castroviejo, S. et al. (eds) 1986-2003. Flora Iberica - plantas vasculares de la península Ibérica e Islas Baleares. Vol. I-VIII, X, XIV. - Real Jard. Bot. CSIC, in Spanish.

Christian, R. R. and Mazzilli, S. 2007. Defining the coast and sentinel ecosystems for coastal observations of global change. - Hydrobiologia 577: 55-70.

Coelho, C. et al. 2009. Potential effects of climate change on northwest Portuguese coastal zones. - ICES J. Mar. Sci. 66, doi: 10.1093/icesjms/fsp132.
Corre, J. J. 1991. The sand dunes and their vegetation along the Mediterranean coast of France. Their likely response to climate change. - Landscape Ecol. 6: 65-75.

Davidson-Arnott, R. G. D. 2005. A conceptual model of the effects of sea level rise on sandy coasts. - J. Coastal Res. 21: 1166-1172.

Dech, J. P. and Maun, M. A. 2005. Zonation of vegetation along a burial gradient on the leeward slopes of Lake Huron sand dunes. - Can. J. Bot. 83: 227-236.

Doing, H. 1985. Coastal foredune zonation and succession in various parts of the world. - Vegetatio 61: 65-75.

Feagin, R. A. and Wu, X. B. 2007. The spatial patterns of functional groups and successional direction in a coastal dune community. - Rangeland Ecol. Manage. 60: 417-425.

Feagin, R. A. et al. 2005a. Coastal erosion, global sea-level rise, and the loss of sand dune plant habitats. - Front. Ecol. Environ. 3: 359-364.

Feagin, R. A. et al. 2005b. Individual versus community level processes and pattern formation in a model of sand dune plant succession. - Ecol. Modell. 183: 435-449.

Forey, E. et al. 2008. The relative importance of disturbance and environmental stress at local and regional scales in French coastal sand dunes. - J. Veg. Sci. 19: 493-502.

Franco, J. A. 1971-1984. Nova flora de Portugal (continente e Açores). Vol. I-II. - Author's edition, in Portuguese.

Franco, J. A. and Afonso, M. L. R. 1994-2003. Nova flora de Portugal (continente e Açores). Vol. III. - Escolar Editora, in Portuguese.

Franks, S. J. and Peterson, C. J. 2003. Burial disturbance leads to facilitation among coastal dune plants. - Plant Ecol. 168: $13-21$.

Freestone, A. L. and Nordstrom, K. F. 2001. Early development of vegetation in restored dune plant microhabitats on a nourished beach at Ocean City, New Jersey. - J. Coastal Conserv. 7: 105-116.

García-Mora, M. R. et al. 1999. Plant functional types in coastal foredunes in relation to environmental stress and disturbance. - J. Veg. Sci. 10: 27-34.

Granja, H. M. and Carvalho, G. S. 1992. Dunes and Holocene deposits of the coastal zone of Portugal, north Mondego cape. - In: Carter, R. W. G. et al. (eds), Coastal dunes (geomorphology, ecology and management for conservation). Balkema, pp. 43-50.

Granja, H. M. 1997. Bad practice in the coastal zone of Portugal. - Coastline EUCC 6: 16-17.

Greaver, T. L. and Sternberg, L. S. L. 2007. Fluctuating deposition of ocean water drives plant function on coastal sand dunes. - Global Change Biol. 13: 216-223.

Henriques, R. 2007. Monitorização da zona costeira tendo em vista a sua vulnerabilidade. Aplicação à zona costeira noroeste de Portugal. - PhD thesis, Univ. of Minho., in Portuguese.

Hesp, P. A. and Martínez, M. L. 2007. Disturbance processes and dynamics in coastal dunes. - In: Johnson, E. A. and Miyanishi, K. (eds), Plant disturbance ecology. The process and the response. Academic Press, Elsevier, pp. 215-247.

IPCC 2007. Climate change 2007: the physical science basis. Contribution of working group I to the Fourth Assessment Report of the Intergovernmental Panel on Climate Change (Solomon, S. et al. (eds)), Cambridge Univ. Press.

Isermann, M. 2005. Soil $\mathrm{pH}$ and species diversity in coastal dunes. - Plant Ecol. 178: 111-120. 
Kerr, R. A. 2007. Global warming is changing the world. - Science 316: 188-190.

Legendre, P. and Legendre, L. 1998. Numerical ecology - developments in environmental modelling, 2nd ed. - Elsevier.

Levin, N. et al. 2006. The spatial and temporal variability of sand erosion across a stabilizing coastal dune field. - Sedimentology 53: 697-715.

Levin, N. et al. 2008. A field quantification of coastal dune perennial plants as indicators of surface stability, erosion or deposition. - Sedimentology 55: 751-772.

Lomba, A. et al. 2006. Towards an interdisciplinary methodology for the indication of stability conditions in coastal areas. - In: Forkiewiez, M. (ed.), Integrated coastal zone management - theory and practice. Proc. Int. Conf. Littoral 2006, pp. 142-146.

Lomba, A. et al. 2008. Endemic sand-dune vegetation from northwest Iberian peninsula: diversity, dynamics and significance for bioindication and monitoring of coastal landscapes. - J. Coastal Res. 24: 113-121.

Lortie, C. J. and Cushman, J. H. 2007. Effects of a directional abiotic gradient on plant community dynamics and invasion in a coastal dune system. - J. Ecol. 95: 468-481.

Loureiro, E. and Granja, H. M. 2001. Short-term morphodynamics of a shingle beach (Esposende, northwest Portugal). - In: Packham, J. R. et al. (eds), Ecology and geomorphology of coastal shingle. Westbury Academic and Scientific Publishing, pp.148-159.

Martínez, M. L. et al. 2006. Assessment of coastal dune vulnerability to natural and anthropogenic disturbances along the Gulf of Mexico. - Environ. Conserv. 33: 109-117.

Martínez, M. L. et al. 2007. The coasts of our world: ecological, economic and social importance. - Ecol. Econ. 63: 254-272.

McGarigal, K. and Cushman, S. A. 2005. The gradient concept of landscape structure. - In: Wiens, J. and Moss, M. (eds), Issues and perspectives in ecology. Cambridge Univ. Press, pp. 112-119.

Maun, M. A. and Perumal, J. 1999. Zonation of vegetation on lacustrine coastal dunes: effects of burial by sand. - Ecol. Lett. 2: 14-18.

Mayoral, O. and Gómez-Serrano, M. A. 2002. Situación y ecología de Otanthus maritimus (L.) Hoffmanns. and Link (Compositae) en la Comunidad Valenciana. - Dugastella 3: 13-19.

MEA 2005. Ecosystems and human well-being: current state and trends. Vol. 1. Findings of the condition and trends working group of the Millennium Ecosystem Assessment. - Island Press.

Meerkerk, A. L. et al. 2007. Sand transport dynamics after a foredune breach: a case study from Schoorl, the Netherlands. - Geomorphology 86: 52-60.

Niemeijer, D. and de Groot, R. S. 2008. A conceptual framework for selecting environmental indicator sets. - Ecol. Indicat. 8: 14-25.

Nordstrom, K. F. et al. 2007. Changes in topography and vegetation near gaps in a protective foredune. - Ocean Coastal Manage. 50: 945-959.

Rivas-Martínez, S. et al. 2002. Vascular plant communities of Spain and Portugal (addenda to the syntaxonomical checklist of 2001). - Itinera Geobot. 15: 5-922.

Rozé, F. and Lemauviel, S. 2004. Sand dune restoration in north Brittany, France: a 10-year monitoring study. - Restor. Ecol. 12: 29-35.

Saye, S. E. et al. 2005. Beach-dune morphological relationships and erosion/accretion: an investigation at five sites in England and Wales using LIDAR data. - Geomorphology 72 128-155.

Schlacher, T. A. et al. 2007. Sandy beaches at the brink. - Divers. Distrib. 13: 556-560.

Sherman, D. et al. 2007. Vertical mass-flux gradients in aeolian saltation. - 2007 Annual Geography Meeting, San Francisco.

StatSoft 2008. Statistica (data analysis software system), ver. 8.0. - <www.statsoft.com>.

ter Braak, C. J. F. and Smilauer, P. 2002. Canoco reference manual and Canodraw for Windows user's guide: software for canonical community ordination, ver. 4.5. - Kluwer.

Thuiller, W. 2007. Climate change and the ecologist. - Nature 448: 550-552.

Urbanski, J. A. 2001. The impact of sea-level rise along the Polish Baltic coast. - J. Coastal Conserv. 7: 155-162.

Veech, J. A. et al. 2002. The additive partitioning of species diversity: recent revival of an old idea. - Oikos 99: 3-9.

Wilson, J. B. and Sykes, M. T. 1999. Is zonation on coastal sand dunes determined primarily by sand burial or by salt spray? A test in New Zealand dunes. - Ecol. Lett. 2: 233-236.

Wilson, M. A. et al. 2005. Integrated assessment and valuation of ecosystem goods and services provided by coastal systems. - In: Wilson, J. G. (ed.), The intertidal ecosystem: the value of Ireland's shores. Royal Irish Academy, pp. 1-24. 
Appendix 1. Nomenclature and codes of plant taxa cited in text, tables and diagrams.

Scientific names of plant taxa are mostly according to Castroviejo et al. (1986-2003) as far as issued, and Franco (1971-1984) and Franco and Afonso (1994-2003) for other groups. Names of subspecies are used in a binomial form throughout the text for simplicity (e.g. Ammophila arundinacea instead of Ammophila arenaria ssp. arundinacea).

Code: plant taxon

Aa: Ammophila arenaria (L.) Link ssp. arundinacea H. Lindb. fil.

Ac: Artemisia crithmifolia L.

$\mathrm{Cm}$ : Crucianella maritima L.

Cs: Calystegia soldanella (L.) R. Br.

Eb: Elytrigia juncea (L.) Nevski ssp. boreatlantica (Simonet \& Guin.) Hyl.

Em: Eryngium maritimum L.

Ep: Euphorbia paralias L.

Lt: Leontodon taraxacoides (Vil.) Mérat ssp. taraxacoides

$\mathrm{Mm}$ : Medicago marina L.

Om: Otanthus maritimus (L.) Hoffmanns. \& Link

Pm: Pancratium maritimum L.

$\mathrm{Sn}$ : Silene niceensis All. 